\title{
Association of interleukin-8 gene polymorphisms in HIV patients with opportunistic infections in Limpopo Province, South Africa
}

\author{
G.A. Dzhivhuho', T.C. Nangammbi² and A. Samie ${ }^{3}$ \\ 1Division of Medical Virology, Institute of Infectious Disease and Molecular Medicine, \\ Faculty of Health Sciences, University of Cape Town, Rondebosch, South Africa \\ 2Department of Nature Conservation, Tshwane University of Technology, Pretoria, \\ South Africa \\ ${ }^{3}$ Molecular Parasitology and Opportunistic Infections Program, \\ Department of Microbiology, School of Mathematical and Natural Sciences, \\ University of Venda, Thohoyandou, South Africa. \\ Corresponding author: A. Samie \\ E-mail: samie.amidou@univen.ac.za / samieamidou@yahoo.com \\ Genet. Mol. Res. 15 (1): gmr.15017466 \\ Received August 18, 2015 \\ Accepted December 3, 2015 \\ Published March 11, 2016 \\ DOI http://dx.doi.org/10.4238/gmr.15017466
}

\begin{abstract}
Opportunistic infections (Ols) are common among human immunodeficiency virus (HIV) patients; however, genetic susceptibility to these infections has not been studied. Recent studies have shown that interleukin-8 (IL-8)A/T genotype carriers are more susceptible to a variety of diseases. In this study, we showed the effects of $I L-8$ gene polymorphisms on Ols and symptoms such as sexually transmitted diseases (STDs), tuberculosis (TB), diarrhea, shortness of breath, weight loss, and viral load, in HIV and acquired immunodeficiency syndrome patients. Genomic DNA was purified from mouthwash samples collected from patients attending HIV centers in the Vhembe district. The IL-8 (-251) A/T locus was genotyped using allele-specific polymerase chain reaction followed by agarose gel electrophoresis. The results showed a weak association between the IL-8 AA
\end{abstract}


genotype and Ols such as STDs $(P=0.143)$, diarrhea $(P=0.906)$, and TB $(P=$ 0.762). Significant associations were found between the IL-8AT genotype and weight loss $(P=0.019)$, shortness of breath $(P=0.043)$, and skin problems $(P=0.003)$. Low viral load was also found to be significantly associated with $I L-8$ AA genotype $(P=0.009)$. The present study suggests that different $I L-8$ genotypes are associated with resistance to various Ols. However, further studies using larger samples sizes are needed to confirm this hypothesis.

Key words: Interleukin-8; Gene polymorphism; HIV; AIDS; Opportunistic infections; Association studies

\section{INTRODUCTION}

Inflammatory processes are important components of the defense mechanisms of the body. Despite their useful function, inflammatory responses may be greater than required to control the initial impact of infections (Adrie and Pinsky, 2000). Thus, inflammatory processes may injure a variety of organs and tissues rather than remove pathogens and promote healing (Chiche et al., 2001). Opportunistic infections (Ols) are one of the most important causes of morbidity and mortality among patients with human immunodeficiency virus (HIV) infections and acquired immunodeficiency syndrome (AIDS). These opportunistic infections occur when the virus continuously damages the immune system such that the immune system can no longer respond to infections. HIV attacks cells of the human immune system, mainly CD4 positive T cells and macrophages, which are key components of the cellular immune system. Cytokines are key protein regulators of host immunity that trigger inflammation in response to infection (Li et al., 2012). This inflammation is associated with the onset of opportunistic infections in HIV and AIDS patients.

Genetic polymorphisms in cytokines have emerged in recent years as important factors of disease susceptibility and severity. Polymorphic variants of several cytokine genes are thought to play important roles in determining how individuals respond to various environmental conditions, including inflammation, at the cellular level (Mustapha et al., 2012). Various studies continue to show that host cytokine responses are genetically determined and polymorphic (Kennedy et al., 2012). In particular, interleukin-8 (IL-8) is considered to be a major polymorphonuclear neutrophil chemoattractant cytokine in bacterial infections (Abul et al., 2001).

The study of genetic variation associated with disease is an exciting area of medical investigation that explains why some patients quickly succumb to disease when other patients with the same infection remain healthy longer. Biomedical and genetic studies have shown the effects of $I L-8$ gene polymorphisms in the pathogenesis of chronic inflammatory diseases, such as cancer (Snoussi et al., 2010), tuberculosis (TB) (Otsuka et al., 2005), and other infections. Nevertheless, no studies have investigated the effects of IL-8 on Ols in HIV patients. In this study, we aimed to identify potential associations between the $I L-8$ gene and Ols in HIV patients. The $I L-8$ gene was genotyped to determine the distribution of IL-8 genotypes (AA, AT, TT) and to identify any association between IL-8 gene polymorphisms and Ols in the Limpopo Province of South Africa.

\section{MATERIAL AND METHODS}

\section{Recruitment of subjects and sample collection}

The study was approved by the Research Review Board and Ethics Committee of the 
University of Venda (UNIVEN). The objectives of the study were explained to the patients and written consent was obtained before the administration of the questionnaires and sample collection. Questionnaires were structured to obtain information regarding gender, hospital, treatment taken, and marital status. Mouthwash samples were collected from a total of 201 patients randomly selected from three different hospitals: Donald Frazer, Elim, and Tshilidzini in the Limpopo Province of South Africa. Other samples were collected at UNIVEN. Patients' files were consulted when needed with permission from the hospital review board and the Department of Health, Polokwane. Samples were transported to the molecular genetics laboratory at UNIVEN in a cooler box with ice. Upon arrival to the laboratory, samples were centrifuged at $500 \mathrm{~g}$ for $15 \mathrm{~min}$. The resulting pellet was transferred to a 2-mL Eppendorf tube and kept in the freezer at $-20^{\circ} \mathrm{C}$ until further use.

\section{DNA extraction and genotyping}

Genomic DNA was extracted from the mouthwash and purified using the Blood Extraction kit (Sigma-Aldrich, Germany) as recommended by the manufacturer. An allele-specific polymerase chain reaction (AS-PCR) was performed to detect the polymorphisms at position -251 of the IL-8 gene promoter region. Beta-globin specific primers were used as an internal control. A PCR mixture was prepared and consisted of $5 \mu \mathrm{L}$ genomic DNA, $10 \mu \mathrm{L}$ KAPA ReadyMix Taq polymerase (Kapa Biosystems, Cape Town, South Africa), $0.3 \mu \mathrm{L}$ each specific and common primer, and nucleasefree water to a final volume of $20 \mu \mathrm{L}$. The primers used were 5'-CTAGAAATAAAAAAGCATACAA-3'; (-251A) 5'- CTAGAAATAAAAAAGCATACAT-3' (-251T); and the common primer 5'- AATACGGAGT ATGACGAAA-3'. These primers yielded a PCR product of about $200 \mathrm{bp}$, as described by Snoussi et al. (2010). AS-PCR cycling conditions were as follows: predenaturation at $96^{\circ} \mathrm{C}$ for $10 \mathrm{~min}$, a touchdown procedure of $25 \mathrm{~s}$ at $95^{\circ} \mathrm{C}$ followed by annealing for $45 \mathrm{~s}$ at temperatures decreasing from $55^{\circ} \mathrm{C}$ (four cycles) to $50^{\circ} \mathrm{C}\left(25\right.$ cycles), and elongation at $72^{\circ} \mathrm{C}$ for $40 \mathrm{~s}$. PCR products were stored at $10^{\circ} \mathrm{C}$. The PCR products of the $I L-8$ gene amplification were loaded onto a $1.5 \%$ agarose gel and visualized under the gel documentation system (GBox, Vacutec, Pretoria, South Africa).

\section{Statistical analysis}

All results were analyzed using the Statistical Package for Social Science (SPSS, Inc., 2009, Chicago, IL, USA) version 19 Windows program. Pearson's chi-square test and binary analysis were used to determine the potential association between the genotype distribution $I L-8$ and the different demographic and clinical characteristics of the patients. Comparisons of frequencies for the two groups were tested by the chi-square test. Crude odds ratios as estimates of the relative risk were calculated with a 95\% confidence interval. The chi-square statistics were used to find Pearson's chi-square significance and likelihood ratios.

\section{RESULTS}

\section{Demographic information of the participants}

All participants were grouped according to gender, place where collection took place, and marital status. A majority of the participants were females (61.15\%) and age varied between 13 and 73 years. From the entire population, 89 (47.34\%) individuals were from Donald Fraser, 49 $(26.06 \%)$ were from Tshilidzini, 36 (19.15\%) were from Elim, and 14 (7.45\%) were from UNIVEN 
(Table 1). Most infections (86\%) were reported to be by sexual intercourse while $2.6 \%$ were from mother-to-child transmission. PCR amplification revealed the genotypes. Amplification of the $I L-8 \mathrm{~A}$ allele produced bands approximately $200 \mathrm{bp}$ long (Figure 1). Amplification of the $I L-8 \mathrm{~T}$ allele also produced bands approximately 200 bp in size. Genotypes were determined based on bands that appear as homozygotes or heterozygotes.

Table 1. Demographic information of the participants according to gender, location, treatment, and marital status.

\begin{tabular}{|c|c|}
\hline Characteristics & Total Number of Individuals $=188(100 \%)$ \\
\hline \multicolumn{2}{|l|}{ Gender } \\
\hline Female & $130(61.15 \%)$ \\
\hline Male & $58(30.85 \%)$ \\
\hline \multicolumn{2}{|l|}{ Location } \\
\hline Donald Frazer & $89(47.34 \%)$ \\
\hline Tshilidzini & $49(26.06 \%)$ \\
\hline Elim & $36(19.15 \%)$ \\
\hline UNIVEN & $14(7.45 \%)$ \\
\hline \multicolumn{2}{|l|}{ Treatment } \\
\hline Antiretroviral therapy (ART) & $97(51.60 \%)$ \\
\hline Prophylaxis & $80(43.55 \%)$ \\
\hline Vitamin B Complex & $60(31.91 \%)$ \\
\hline Bactrim & $50(26.60 \%)$ \\
\hline General antibiotic & $27(14.36 \%)$ \\
\hline Multi Vitamin Concentrate (intravenous infusion) (MVI) & $11(5.85 \%)$ \\
\hline \multicolumn{2}{|l|}{ Marital status } \\
\hline Single & $80(42.55 \%)$ \\
\hline Married & $61(32.45 \%)$ \\
\hline Widow & $27(14.36 \%)$ \\
\hline Divorced & $20(10.64 \%)$ \\
\hline \multicolumn{2}{|l|}{ Age group } \\
\hline$<25$ years & $12(6.38 \%)$ \\
\hline $25-45$ years & $105(55.85 \%)$ \\
\hline$>45$ years & $71(37.77 \%)$ \\
\hline
\end{tabular}

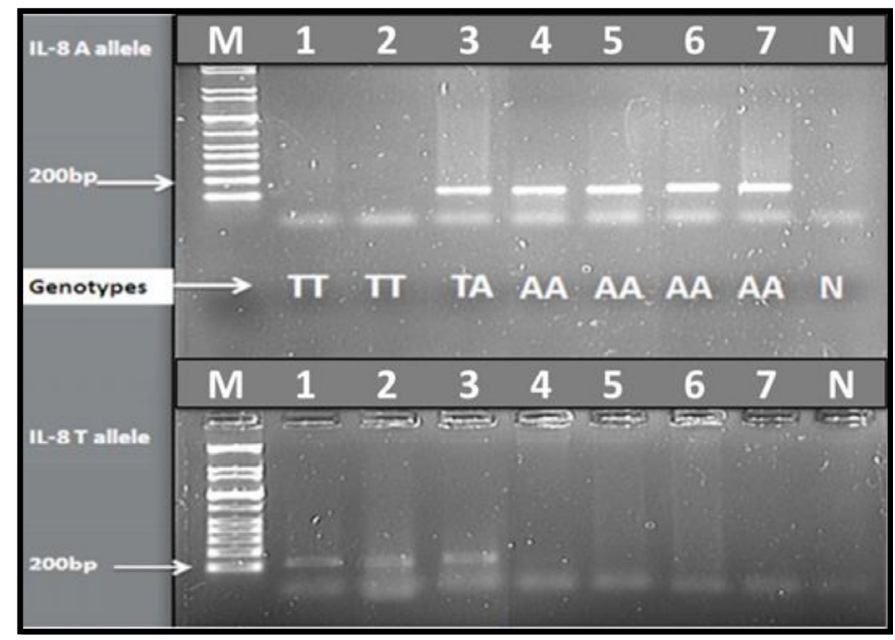

Figure 1. Allele-specific amplification products for the $I L-8(-251) A$ and T alleles. Lane $M$ is the marker (1 kb ladder). Lane $N$ is the negative control. Numbers represent samples (lanes 1-7). Genotypes are indicated in the middle of the gels as TT, AA, or TA. 


\section{General distribution of the IL-8 genotypes}

Only 188 of the 201 samples were successfully amplified. These 188 samples were analyzed. The homozygous IL-8 AA genotype was predominant in the population (71\%), followed by the heterozygous IL-8 AT (25\%) genotype and the homozygous IL-8 TT genotype (4\%) (Figure 2).

\section{IL-8 Genotype Distribution}

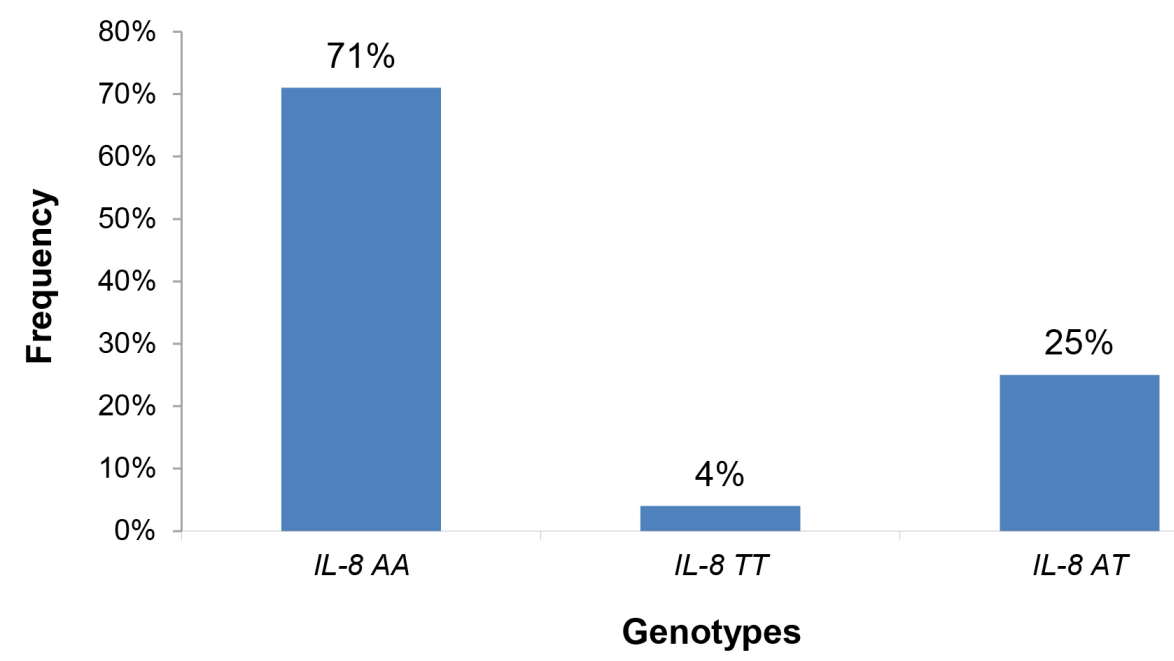

Figure 2. Distribution of $I L-8$ genotypes across the study population.

\section{IL-8 genotype polymorphisms correlated to opportunistic infections}

Several Ols and symptoms were reported by the participants, including sexually-transmitted diseases (STDs), TB, diarrhea, and skin infections. Table 2 shows the distribution of the genotypes in relation to the occurrence of opportunistic infections and symptoms as reported by the patients. Of the 138 patients without STDs, $68 \%$ had the AA genotype. Of the 37 patients with STDs, $81 \%$ had the AA genotype. However, the difference was not significant $\left(\chi^{2}{ }_{154}=2.142, P=0.143\right)$. The TT genotype did not show a significant difference between patients with STDs and patients without STDs $(P=$ 0.784). A significant association was found between the AT genotype and current skin problems $(P=$ $0.003)$, loss of weight $(P=0.019)$ and shortness of breath $(P=0.043)$ (Table 2).

\section{IL-8 genotype polymorphisms in relation to immunological characteristics of the participants}

The CD4 count was reported for some patients from their files as 162 well as the viral load. Participants with viral loads less than 25 copies (or undetectable) also predominantly had the AA genotype $\left(\chi_{164}^{2}=9.367 ; P=0.009\right)$. A majority of the participants with CD4 counts less than 50 cells/ $\mathrm{LL}$ carried the AA genotype, but the difference was not significant $(P=0.717)$. Of the 99 individuals with $C D 4$ counts less than 200 cells/ $\mu \mathrm{L}, 73$ (73.7\%) carried the AA genotype, 23 (23.2\%) carried the AT genotype, and $3(3.1 \%)$ carried the TT genotype with low significance $(P=0.311)$ (Table 3). 
Table 2. IL-8 genotype distributions in relation to opportunistic infections.

\begin{tabular}{|c|c|c|c|c|c|c|}
\hline \multirow[t]{2}{*}{ GTYPs vs Ols } & \multicolumn{2}{|c|}{ Frequency } & \multirow[t]{2}{*}{ Total } & \multirow[t]{2}{*}{ OR 95\% } & \multirow[t]{2}{*}{$\chi^{2}$} & \multirow[t]{2}{*}{$P$ value } \\
\hline & Yes & No & & & & \\
\hline IL-8 GTYP vs STD & $\mathrm{N}=37$ & $N=138$ & $175(100 \%)$ & - & 2.833 & 0.243 \\
\hline AA & $30(81.1 \%)$ & $95(68.8 \%)$ & $125(71.4 \%)$ & 1.940 & 2.142 & 0.143 \\
\hline AT & $5(13.5 \%)$ & $37(26.8 \%)$ & $42(24.0 \%)$ & 0.427 & 2.829 & 0.093 \\
\hline TT & $2(5.4 \%)$ & $6(4.3 \%)$ & $8(4.6 \%)$ & 1.257 & 0.075 & 0.784 \\
\hline IL-8 GTYP vs TB & $\mathrm{N}=22$ & $N=143$ & $165(100 \%)$ & - & 1.858 & 0.395 \\
\hline AA & $15(68.2 \%)$ & $102(71.3 \%)$ & $117(70.9 \%)$ & 0.861 & 0.092 & 0.762 \\
\hline AT & $7(31.8 \%)$ & $33(23.1 \%)$ & $40(24.2 \%)$ & 1.556 & 0.793 & 0.373 \\
\hline TT & $0(0.0 \%)$ & $8(5.6 \%)$ & $8(4.8 \%)$ & 0.944 & 1.293 & 0.255 \\
\hline IL-8 GTYP vs Dia. & $\mathrm{N}=36$ & $N=139$ & $175(100 \%)$ & 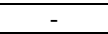 & 0.342 & 0.843 \\
\hline AA & $26(72.2 \%)$ & $99(71.2 \%)$ & $125(71.4 \%)$ & 1.051 & 0.014 & 0.906 \\
\hline AT & $9(25.0 \%)$ & $33(23.7 \%)$ & $42(24.0 \%)$ & 1.071 & 0.025 & 0.875 \\
\hline TT & $1(2.8 \%)$ & $7(5.0 \%)$ & $8(4.6 \%)$ & 0.539 & 0.334 & 0.563 \\
\hline IL-8 GTYP vs PSP & $\mathrm{N}=51$ & $\mathrm{~N}=112$ & $163(100 \%)$ & - & 3.141 & 0.208 \\
\hline AA & $41(80.4 \%)$ & $75(67.0 \%)$ & $116(71.2 \%)$ & 2.023 & 3.079 & 0.079 \\
\hline AT & $8(15.7 \%)$ & $31(27.7 \%)$ & $39(23.9 \%)$ & 0.486 & 2.769 & 0.096 \\
\hline TT & $2(3.9 \%)$ & $6(5.4 \%)$ & $8(4.9 \%)$ & 0.721 & 0.155 & 0.694 \\
\hline IL-8 GTYP vs CSP & $\mathrm{N}=21$ & $\mathrm{~N}=46$ & $67(100 \%)$ & - & 8.913 & 0.012 \\
\hline AA & $20(95.2 \%)$ & $30(65.2 \%)$ & $50(74.6 \%)$ & 10.667 & 6.862 & 0.009 \\
\hline AT & $0(0.0 \%)$ & $15(32.6 \%)$ & $15(22.4 \%)$ & 13.555 & 8.823 & 0.003 \\
\hline TT & $1(4.8 \%)$ & $1(2.2 \%)$ & $2(3.0 \%)$ & 2.250 & 0.333 & 0.564 \\
\hline IL-8 GTYP vs LOW & $\mathrm{N}=21$ & $\mathrm{~N}=107$ & $128(100 \%)$ & 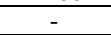 & 5.598 & 0.061 \\
\hline AA & $18(85.7 \%)$ & $70(65.4 \%)$ & $88(68.8 \%)$ & 3.171 & 3.365 & 0.067 \\
\hline AT & $1(4.8 \%)$ & $31(29.0 \%)$ & $32(25.0 \%)$ & 0.123 & 5.488 & 0.019 \\
\hline TT & $2(9.5 \%)$ & $6(5.6 \%)$ & $8(6.3 \%)$ & 1.772 & 0.460 & 0.498 \\
\hline IL-8 GTYP vs SOB & $\mathrm{N}=29$ & $N=130$ & $159(100 \%)$ & - & 3.654 & 0.161 \\
\hline AA & $24(82.8 \%)$ & $89(68.5 \%)$ & $113(71.1 \%)$ & 2.211 & 2.357 & 0.125 \\
\hline AT & $3(10.3 \%)$ & $35(26.9 \%)$ & $38(23.9 \%)$ & 0.313 & 3.583 & 0.043 \\
\hline TT & $2(6.9 \%)$ & $6(4.6 \%)$ & $8(5.0 \%)$ & 1.531 & 0.258 & 0.611 \\
\hline
\end{tabular}

GTYP = genotypes; $I L-8$ = interleukin-8; Ols = opportunistic infections; STD = sexually-transmitted diseases; TB = tuberculosis; Dia. = diarrhea; $\mathrm{PSP}=$ past skin problem; CSP = current skin problem; LOW = loss of weight; $\mathrm{SOB}=$ shortness of breath; OR $=$ odds ratio. Significance: ${ }^{*} P<0.05$.

Table 3. IL-8 genotypes in relation to immunological characteristics of the participants.

\begin{tabular}{|c|c|c|c|c|c|c|}
\hline GTYP vs IC & \multicolumn{2}{|c|}{ Frequency } & Total & OR & $\overline{\chi^{2}}$ & $P$ value \\
\hline IL-8 GTYP vs VL & $\begin{array}{c}<25 \text { copies } \\
29(100.0 \%)\end{array}$ & $\begin{array}{c}>25 \text { copies } \\
13(100.0 \%)\end{array}$ & $42(100.0 \%)$ & - & 9.543 & 0.049 \\
\hline AA & $22(75.9 \%)$ & $5(38.5 \%)$ & $27(64.3 \%)$ & 0.199 & 5.464 & 0.019 \\
\hline AT & $5(17.2 \%)$ & $5(38.5 \%)$ & $10(23.8 \%)$ & 3 & 2.228 & 0.136 \\
\hline TT & $2(6.9 \%)$ & $3(23.1 \%)$ & $5(11.9 \%)$ & 4 & 2.241 & 0.134 \\
\hline IL-8 GTYP vs CD4 & $\begin{array}{l}<50 \text { cells/ } / \mu \mathrm{L} \\
33(100.0 \%)\end{array}$ & $\begin{array}{c}>50 \text { cells/ } / \mu \mathrm{L} \\
129(100.0 \%)\end{array}$ & $162(100.0 \%)$ & - & 0.454 & 0.797 \\
\hline AA & $23(69.7 \%)$ & $94(72.9 \%)$ & $117(72.2 \%)$ & 0.856 & 0.132 & 0.717 \\
\hline AT & $9(27.3 \%)$ & $29(22.5 \%)$ & $38(23.5 \%)$ & 1.293 & 0.336 & 0.562 \\
\hline TT & $1(3.0 \%)$ & $6(4.7 \%)$ & $7(4.3 \%)$ & 0.641 & 0.167 & 0.683 \\
\hline IL-8 GTYP vs CD4 & $\begin{array}{c}<200 \text { cells/ } / \mathrm{L} \\
99(100.0 \%)\end{array}$ & $\begin{array}{c}>200 \text { cells } / \mu \mathrm{L} \\
63(100.0 \%)\end{array}$ & $162(100.0 \%)$ & - & 1.068 & 0.586 \\
\hline AA & $73(73.7 \%)$ & $44(69.8 \%)$ & $117(72.2 \%)$ & 1.212 & 0.291 & 0.589 \\
\hline AT & $23(23.2 \%)$ & $15(23.8 \%)$ & $38(23.5 \%)$ & 0.968 & 0.007 & 0.933 \\
\hline TT & $3(3.1 \%)$ & $4(6.3 \%)$ & $7(4.3 \%)$ & 0.461 & 1.026 & 0.311 \\
\hline
\end{tabular}

GTYP = genotypes; IC = immunological characteristics; $I L-8=$ interleukin-8; VL = viral load; CD4 = cluster of differentiation; $\mathrm{OR}=$ odds ratio. Significance: ${ }^{*} \mathrm{P}<0.05$.

\section{DISCUSSION}

IL-8 is an important chemokine that acts as a chemoattractant for neutrophils (Kim et al., 
2009). This chemokine is widely studied because of its associations with various diseases, such as respiratory infections, urinary tract infections, and cancer (Falfán-Valencia et al., 2012). The pathogenesis of urinary tract inflammation was reported to involve the recruitment of neutrophils into the urinary tracts and chemokine receptor interactions that result in tissue damages (Zaffanello et al., 2010). Studies in vitro have shown that the IL-8 (-251) A allele tends to be associated with increased $I L-8$ production and tissue damage in lipopolysaccharide-stimulated whole blood (Hull et al., 2000). Most studies have thus suggested that the IL-8 (-251) AA genotype is associated with increased risks of various diseases, such as breast cancer (Snoussi et al., 2010), prostate cancer (McCarron et al., 2002), enteroaggregative Escherichia coli diarrhea (Jiang et al., 2003), and TB (Ma et al., 2003). Most of these diseases can cause serious harm to an HIV patient because they further compromise the immune system and allow HIV to progress rapidly to AIDS, resulting in millions of deaths every year.

The present study found that the IL-8 AA genotype is predominant in our study population in Limpopo. However, a study conducted in Texas, USA by Garey et al. (2010) revealed the $I L-8$ heterozygote to be predominant (27\% AA, 53\% AT, and 20\% TT). In a study by Okada et al. (2009), the A allele frequency in control subjects was 0.48 in the Uzbekistan Republic. This allele frequency was similar to previous reports for Caucasian populations. They also indicated that the IL-8 -251 AA genotype was associated with higher anti-p53 antibodies. It can therefore be estimated that the majority of the population in our region could be more susceptible to infections and cancer.

Although we did not investigate associations between this genotype and cancer in our population, we found that the AA genotype was associated with skin problems. Skin problems reported by patients in our study were not specific and covered different problems, such as Kaposi' sarcoma, night burn, and dermatitis, some of which are cancers. In a meta-analysis by Xue et al. (2012), the IL-8 -251 AA genotype was associated with the overall risk of developing gastric cancer and might indicate increased susceptibility to overall gastric cancer in Asian populations. Although similar studies have not been conducted in the African population, our results suggest that the patients could be susceptible to these cancers as well. In the present study, the $I L-8$ AA genotype was more common among patients with STDs although the difference was not statistically significant. These STDs generally included burning urination, colored and watery discharges, rush, sores, and genital warts. These results are similar to those previously described by van der Kuyl et al. (2004), who indicated that HIV patients with the AA genotype were more susceptible to AIDS-related Kaposi sarcoma while individuals carrying the TT genotype appeared to be protected. Diarrhea is also common among HIV and AIDS patients and occurs in about $90 \%$ of patients. In our study, diarrhea occurred in about $20 \%$ of patients and was not significantly associated with any genotype. Although we did not establish the causative agent of diarrhea among these patients, results obtained by Jiang et al (2003) found that individuals with the AA or AT genotype at the -251 position in the promoter region of $I L-8$ were more likely to develop symptomatic enteroaggregative $E$. coli infections than those with the TT genotype. It is therefore necessary to further investigate the causes of diarrhea in this population in relation to their genetic background, at least at the -251 position. A highly significant association was found between AA genotype carriers and low viral load (below 25 copies). Since most of our patients were on antiretroviral therapy (ART), it can be argued that drug usage might have improved the viral load of the participants in relation to their CD4 counts. Therefore, further studies are needed to verify the effect of these genotypes in the presence and absence of ARTs. These results indicate that patients carrying the IL-8 AT genotype are less susceptible to most opportunistic infections than IL-8 AA genotype carriers. Hence, this conforms to a similar study in breast cancer (Snoussi et al., 2010), where carriers of the IL-8 AA genotype were 
more susceptible to aggressive breast cancer and TB (Ma et al., 2003). This suggests that the AT genotype might have moderate effects on disease susceptibility, particularly with skin problems and weight loss. Surprisingly, none of the TB patients in our study carried the TT genotype and very few patient IL-8 TT genotype carriers had STDs, diarrhea, shortness of breath, skin problems, or weight loss. This might mean that patients with the IL-8 TT genotype might be resistant to the aforementioned diseases.

The main limitation of this study was the size of the population. The small study size was due to ethical restrictions and the unwillingness of the patients to participate in the study. However, these preliminary results are important to understand the impact of host genetics on the occurrence of Ols and to generate hypotheses for further studies. This study also establishes the association between genetics and biomarkers such as IL-8. To our knowledge, no studies have shown such results. However, a larger sample size is needed to confirm this possible hypothesis. The findings described in the present study indicate that HIV patients in the Vhembe district mostly carried the AA genotype, which has been reported to render the carrier susceptible to several infections in different environments. In addition, our results show that carriers of the $I L-8$ AA genotype might be less susceptible to Ols such as skin problems, shortness of breath, and STDs than carriers of the AT genotype. Further studies are needed using larger populations in order to confirm the effect of these factors on the occurrence of Ols among patients in the region. These genetic markers may define populations that could benefit from therapeutic interventions such as prophylactic antibiotic therapy or vaccination. Our data showed that the TT genotype was protective against TB.

\section{Conflicts of interest}

The authors declare no conflict of interest.

\section{ACKNOWLEDGMENTS}

Research supported by the Research and Publication Committee in the University of Venda and the National Research Foundation.

\section{REFERENCES}

Abul H, Abul A, Khan I, Mathew TC, et al. (2001). Levels of IL-8 and myeloperoxidase in the lungs of pneumonia patients. Mol. Cell. Biochem. 217: 107-112.http://dx.doi.org/10.1023/A:1007264411006

Adrie C and Pinsky MR (2000). The inflammatory balance in human sepsis. Intensive Care Med. 26: 364-375. http://dx.doi. org/10.1007/s001340051169

Chiche JD, Siami S, Dhainaut JF and Mira JP (2001). Cytokine Polymorphisms and Susceptibility to Severe Infectious Diseases. Sepsis 4: 209-215. http://dx.doi.org/10.1023/A:1013222407924

Falfán-Valencia R, Pavón-Romero GF, Camarena A, García MdeL, et al. (2012). The IL1B-511 Polymorphism (rs16944 AA Genotype) Is Increased in Aspirin-Exacerbated Respiratory Disease in Mexican Population. J. Allergy (Cairo) 2012: 741313. http://dx.doi.org/10.1155/2012/741313

Garey KW, Jiang ZD, Ghantoji S, Tam VH, et al. (2010). A common polymorphism in the interleukin-8 gene promoter is associated with an increased risk for recurrent Clostridium difficile infection. Clin. Infect. Dis. 51: 1406-1410. http://dx.doi. org/10.1086/657398

Hull J, Thomson A and Kwiatkowski D (2000). Association of respiratory syncytial virus bronchiolitis with the interleukin 8 gene region in UK families. Thorax 55: 1023-1027. http://dx.doi.org/10.1136/thorax.55.12.1023

Jiang ZD, Okhuysen PC, Guo DC, He R, et al. (2003). Genetic susceptibility to enteroaggregative Escherichia coli diarrhea: polymorphism in the interleukin-8 promotor region. J. Infect. Dis. 188: 506-511.http://dx.doi.org/10.1086/377102

Kennedy RB, Ovsyannikova IG, Pankratz VS, Haralambieva IH, et al. (2012). Genome-wide analysis of polymorphisms associated with cytokine responses in smallpox vaccine recipients. Hum. Genet. 131: 1403-1421. http://dx.doi. org/10.1007/s00439-012-1174-2 
Kim Y, Viana AC, Corbi SCT, Curtis KMDC, et al. (2009). Detection of the single nucleotide polymorphism (rs2227307) in the human interleukin 8 gene using a pcr-rflp assay. Biosci. J. 25: 134-142.

Li WM, Albrecht A and Li M (2012). Inflammation and Pancreatic Cancer: A Tale of Two Cytokines. Cell. Biol. Res. Ther 1: 1. http://dx.doi.org/10.4172/2324-9293.1000e104

Ma X, Reich RA, Wright JA, Tooker HR, et al. (2003). Association between interleukin-8 gene alleles and human susceptibility to tuberculosis disease. J. Infect. Dis. 188: 349-355. http://dx.doi.org/10.1086/376559

McCarron SL, Edwards S, Evans PR, Gibbs R, et al. (2002). Influence of cytokine gene polymorphisms on the development of prostate cancer. Cancer Res. 62: 3369-3372.

Mustapha MA, Shahpudin SN, Aziz AA and Ankathil R (2012). Risk modification of colorectal cancer susceptibility by interleukin-8 -251T>A polymorphism in Malaysians. World J. Gastroenterol. 18: 2668-2673. http://dx.doi.org/10.3748/ wjg.v18.i21.2668

Okada R, Rahimov B, Ahn KS, Abdiev S, et al. (2009). Interleukin-8 T-251A polymorphism was associated with positive anti-p53 antibodies in Uzbekistan population. Nagoya J. Med. Sci. 71: 151-156.

Otsuka Y, Fujino T, Mori N, Sekiguchi J, et al. (2005). Survey of human immunodeficiency virus (HIV)-seropositive patients with mycobacterial infection in Japan. J. Infect. 51: 364-374. http://dx.doi.org/10.1016/j.jinf.2004.12.015

Snoussi K, Mahfoudh W, Bouaouina N, Fekih M, et al. (2010). Combined effects of IL-8 and CXCR2 gene polymorphisms on breast cancer susceptibility and aggressiveness. BMC Cancer 10: 283. http://dx.doi.org/10.1186/1471-2407-10-283

van der Kuyl AC, Polstra AM, Weverling GJ, Zorgdrager F, et al. (2004). An IL-8 gene promoter polymorphism is associated with the risk of the development of AIDS-related Kaposi's sarcoma: a case-control study. AIDS 18: 1206-1208. http:// dx.doi.org/10.1097/00002030-200405210-00016

Xue H, Liu J, Lin B, Wang Z, et al. (2012). A meta-analysis of interleukin-8 -251 promoter polymorphism associated with gastric cancer risk. PLoS One 7: e28083. http://dx.doi.org/10.1371/journal.pone.0028083

Zaffanello M, Malerba G, Cataldi L, Antoniazzi F, et al. (2010). Genetic risk for recurrent urinary tract infections in humans: a systematic review. J. Biomed. Biotechnol. 2010: 321082. http://dx.doi.org/10.1155/2010/321082 